\title{
Article
}

\section{Temporal Geospatial Analysis of COVID-19 Pre-Infection Determinants of Risk in South Carolina}

\author{
Tianchu Lyu ${ }^{1,+}$, Nicole Hair ${ }^{1,+}+\mathbb{D}$, Nicholas Yell ${ }^{2}$, Zhenlong Li ${ }^{3} \mathbb{D}$, Shan Qiao ${ }^{4}$, Chen Liang ${ }^{1, * \mathbb{D}}$ and \\ Xiaoming $\mathrm{Li}^{4}$ (D)
}

check for

updates

Citation: Lyu, T.; Hair, N.; Yell, N.; Li, Z.; Qiao, S.; Liang, C.; Li, X. Temporal Geospatial Analysis of COVID-19 Pre-Infection Determinants of Risk in South Carolina. Int. J. Environ. Res. Public Health 2021, 18, 9673. https:// doi.org/10.3390/ijerph18189673

\section{Academic Editors: Dimitrios}

Paraskevis, Maria Yavropoulou and Sotirios Tsiodras

Received: 3 August 2021

Accepted: 10 September 2021

Published: 14 September 2021

Publisher's Note: MDPI stays neutral with regard to jurisdictional claims in published maps and institutional affiliations.

Copyright: (c) 2021 by the authors. Licensee MDPI, Basel, Switzerland. This article is an open access article distributed under the terms and conditions of the Creative Commons Attribution (CC BY) license (https:// creativecommons.org/licenses/by/ $4.0 /)$.
1 Department of Health Services Policy and Management, Arnold School of Public Health, University of South Carolina, Columbia, SC 29208, USA; tlyu@email.sc.edu (T.L.); hairnl@mailbox.sc.edu (N.H.)

2 Department of Statistics, College of Arts and Sciences, University of South Carolina, Columbia, SC 29208, USA; yelln@email.sc.edu

3 Department of Geography, College of Arts and Sciences, University of South Carolina, Columbia, SC 29208, USA; zhenlong@mailbox.sc.edu

4 Department of Health Promotion, Education, and Behavior, Arnold School of Public Health, University of South Carolina, Columbia, SC 29208, USA; shanqiao@mailbox.sc.edu (S.Q.); xiaoming@mailbox.sc.edu (X.L.)

* Correspondence: cliang@mailbox.sc.edu; Tel.: +1-803-777-8139

+ Equal contribution.

\begin{abstract}
Disparities and their geospatial patterns exist in morbidity and mortality of COVID-19 patients. When it comes to the infection rate, there is a dearth of research with respect to the disparity structure, its geospatial characteristics, and the pre-infection determinants of risk (PIDRs). This work aimed to assess the temporal-geospatial associations between PIDRs and COVID-19 infection at the county level in South Carolina. We used the spatial error model (SEM), spatial lag model (SLM), and conditional autoregressive model (CAR) as global models and the geographically weighted regression model (GWR) as a local model. The data were retrieved from multiple sources including USAFacts, U.S. Census Bureau, and the Population Estimates Program. The percentage of males and the unemployed population were positively associated with geodistributions of COVID-19 infection ( $p$ values $<0.05)$ in global models throughout the time. The percentage of the white population and the obesity rate showed divergent spatial correlations at different times of the pandemic. GWR models fit better than global models, suggesting nonstationary correlations between a region and its neighbors. Characterized by temporal-geospatial patterns, disparities in COVID-19 infection rate and their PIDRs are different from the mortality and morbidity of COVID-19 patients. Our findings suggest the importance of prioritizing different populations and developing tailored interventions at different times of the pandemic.
\end{abstract}

Keywords: COVID-19; healthcare disparities; social determinants of health; spatial analysis; PostAcute Sequelae of SARS-CoV-2 infection

\section{Introduction}

Coronavirus disease 2019 (COVID-19), caused by the Severe Acute Respiratory Syndrome Coronavirus 2 (SARS-CoV-2), is a highly contagious disease that has caused widespread panic and concern across the globe. COVID-19 was the third leading cause of death in 2020. The death rate increased by 15.9\% from 2019 to 2020 [1]. As of September 2020, there have been 41 million confirmed cases and 660 thousand deaths due to COVID19 in the USA [1-3]. Additionally, COVID-19 has had a profound impact on social life and the economy, as closing businesses and social distancing have been common practices to slow the spread of the disease. The U.S. real GDP decreased by $3.5 \%$ in 2020 and was projected to lose at least $\$ 3.2$ trillion due to COVID-19 in a two-year course [4,5].

The burdens of COVID-19 have not been borne equally. Some populations face increased risk for COVID-19 morbidity and mortality [6]. Many studies have reported disparities in the clinical outcomes of patients with COVID-19. For example, studies 
using inpatient data found severe disease progression and poor clinical outcomes of COVID-19 patients to be associated with a set of underlying medical conditions (e.g., hypertension, diabetes, asthma, and heart, liver, and respiratory illnesses), demographics (e.g., male, older age, race/ethnic minority), and social determinants of health (SDOHs) (e.g., lower education and income) [7-11]. A study based on a large cohort in Louisiana comprised of 3,481 COVID-19 patients reported that $76.9 \%$ of the hospitalized cases and $70.6 \%$ of the death cases were among black patients, whereas only $31 \%$ of the state's population is black [12]. While these studies have provided a critical evidence base of disparities in COVID-19 clinical outcomes and implications for medical care for addressing the disparities, they offered limited implications for disparities in the risk of exposure to COVID-19 for the following reasons. First, the findings of these studies are applicable for hospitalized patients but may not be generalizable for outpatients, individuals with mild symptoms, and asymptomatic individuals since these studies are based on inpatient data. The omission of outpatients and individuals with laboratory-confirmed COVID-19 infections but no clinic visits will harm the potential opportunity of exploring risk factors for these populations [13]. Second, using disease severity as the outcome variable does not provide information on SARS-CoV-2 infection and transmission. For example, SARS-CoV-2 transmits more easily in regions with a large proportion of younger people, yet the elderly were found to be at a higher risk of developing poor clinical outcomes [14].

Therefore, it is equally important to curate an evidence base for disparities in the risk of exposure to COVID-19 and the pre-infection determinants of risk (PIDRs) (e.g., demographics, socioeconomics, and prevalence of diseases related to COVID-19 infection) [15-20]. Such an evidence base can be used for understanding disease transmission patterns, identifying vulnerable populations, and proactively mitigating disparities in future pandemics [21]. Existing studies have reported demographic and socioeconomic factors to be related to disparities in the risk of exposure to COVID-19. Different combinations of those determinants lead to different health attributes (e.g., health behaviors and physical conditions), thus influencing the spread of the virus. For example, high-deprivation areas have higher rates of hospitalization and testing [17]. People with a higher income are more likely to engage in self-protecting behavior during the COVID-19 pandemic [18]. Another study reported that the behaviors of wearing masks and using hand hygiene are associated with the female sex and a higher education level among students in the Chinese population [19]. In a primary care cohort, researchers observed a higher risk of COVID-19 infection among people aged 40-64 years, of the male sex, of the black race, and living in urban areas [15]. Incorporating census tract level data with the COVID-19 dataset, Hawkins and colleagues examined the association between socioeconomic indicators and COVID-19 cases at the county level across the USA and found a lower education level and a higher percentage of black residents to be risk factors for the infection [16].

To further explore the associations between PIDRs and COVID-19 transmission, geospatial information is needed. Geographic differences exist across states, counties, and communities in the timing of the SARS-CoV-2 introduction, which are further characterized by population density, local policies, and population composition [14]. Particularly, understanding PIDRs and their geospatial epidemiology is urgently needed for rural states, such as South Carolina, that have a disproportionally low healthcare capacity and high disease burden. It may also provide timely information for post-COVID-19 care, given the emerging reports on the heterogeneity of symptoms in individuals with Post-Acute Sequelae of SARS-CoV-2 infection (PASC) [22,23]. Although the spatially dynamic nature of infectious diseases (e.g., different spatial patterns of transmission) makes geospatial analysis a valuable tool to unveil the epidemiology [24-27], there have been limited studies reporting the geospatial characteristics of PIDRs [14,28-31]. Several studies have reported minority status, age, and other social vulnerabilities to be associated with a higher COVID19 infection, yet spatial patterns were generally not included in the statistical models as independent variables $[28,30,31]$. Fortaleza and colleagues used multivariate regression and found that population density and distance from the state capital are robust predictors 
of COVID-19 prevalence in Brazil [29]. However, the results should be interpreted carefully since the association between population density and COVID-19 infection could be influenced by factors such as different policies being applied to smaller regions [32]. Another study built a correlation matrix between socioeconomic determinants and COVID-19 case rates across the USA and found population density to be highly correlated with COVID-19 prevalence [14].

Although the above studies have collectively suggested possible geospatial characteristics among the disparities in virus transmission, spatial autocorrelation is generally excluded from their statistical models, which limits the statistical power of the findings. The spatial autocorrelation, including global modeling and local modeling approaches, enables the correlation measure of a variable (e.g., PIDRs) with itself across different regions. Spatial global models assume a stationary correlation between a region and its neighbors, whereas spatial local models assume nonstationary correlations between a region and different neighbors. Among a few preliminary studies that adopted spatial autocorrelation, Mollalo and colleagues examined the association between the COVID-19 incidence rate and four county-level explanatory determinants including income inequality, median household income, the percentage of nurse practitioners, and the proportion of the black female population to the total female population across the USA [33]. The authors started with a set of 35 socioeconomic, behavioral, topographic, and demographic explanatory variables. After a stepwise forward procedure and correlation analysis, they choose to keep four of these variables in their final model and found that geographically weighted regression (GWR) models best explained the variations, suggesting the existence of spatial autocorrelation and different vulnerabilities across the counties. Despite the application of highly appropriate geospatial methods, the study could have better interpreted the disparity structure if demographic determinants such as age, sex, and race were included in the analysis. Additionally, because these studies were based on analyses of cross-sectional data, they did not specify whether and how observed relationships between COVID-19 outcomes and PIDRs vary at different points in time as the pandemic evolved. Moreover, there is increased endogeneity in these analyses because they focused on large geographic regions within which different regional policies might have a greater impact on the COVID-19 prevalence as compared with the explanatory variables. Existing evidence suggests that government responses and socioeconomic determinants have played an important role in the transmission of SARS-CoV-2, which differs geographically [34]. Another similar study included demographics but still suffered from the same endogeneity problem [35].

Building on these existing studies, we sought to assess the association between PIDRs (including demographics, socioeconomics, and prevalence of diseases related to COVID19 infection) and COVID-19 infection at the county level in South Carolina at different timepoints amid the pandemic. The heterogeneity in the virus spread in South Carolina suggests that different PIDRs in certain areas could enhance or inhibit the transmission of COVID-19. Within the smaller geographic scale of one state, the heterogeneous impacts of different regional policies could be largely mitigated, and the multi-source South Carolina surveillance data were sufficient for conducting geospatial analyses. Although there has been no statewide mask mandate in South Carolina, regional mask ordinances covered most of the regions by July 2021 [36]. The findings of this study form an evidence base for temporal geospatial disparities in the risk of exposure to COVID-19 and the associated PIDRs. The identified PIDRs may also shed light on the populations and regions vulnerable to PASC in South Carolina during post-COVID-19 care.

\section{Materials and Methods}

\subsection{Model Selection}

We selected six time windows to represent COVID-19 cases at different times of the pandemic. South Carolina began tracking COVID-19 cases in early March of 2020 and the number of daily new cases began to rise until July 2020 when the daily number of new cases began to fluctuate. We calculated the average cumulated case numbers in a sliding 
window of seven days (15th \pm 3 days) for every month between July and December of 2020.

The US Centers for Disease Control and Prevention (CDC) have provided a list of risk factors of COVID-19 severity such as age and existing medical conditions [37]. As discussed in the introduction, the PIDRs for COVID-19 severity can be very different from the PIDRs for COVID-19 infection. Based on previous studies, Snyder and Parks presented a welldeveloped risk factor index framework for COVID-19 community vulnerability which was defined as "the potential decrease in the wellbeing of a community before and during/after the pandemic, taking into account health, social, and economic conditions" [38-40]. The index is divided into four major sections (e.g., ecological, social, health, and economic) [39]. Inspired by their study and based on data availability in South Carolina, we began with 15 different variables related to the four sections of the index including sex, age, race, median household income, population density, uninsured rate, poverty percentage, high school degree rate, college degree rate, unemployment rate, physical inactivity rate, obesity rate, smoking prevalence, medical doctors per 10,000 people, and nurse practitioners per 10,000 people (Table 1). Among the candidate variables, age, sex, and population density represent ecological variables; uninsured rate, education levels, race, medical doctor abundance, and nurse practitioner abundance are social variables; obesity rate, physical inactivity rate, and smoking prevalence are health variables; and income, poverty rate, and unemployment rate are economic variables.

Table 1. Candidate explanatory variables and definitions.

\begin{tabular}{|c|c|c|}
\hline Theme & Variable & Definition \\
\hline \multirow{3}{*}{ Ecological } & Age & Median age \\
\hline & Sex & Percentage of male population to the total population \\
\hline & Population density & Population per square mile \\
\hline \multirow{6}{*}{ Social } & Uninsured rate & Percentage of population under 65 years old without health insurance \\
\hline & High school degree rate & Percentage of population with a high school or higher degree \\
\hline & College degree rate & Percentage of population with a college or higher degree \\
\hline & Race & Percentage of white population to the total population \\
\hline & Medical doctor abundance & The number of medical doctors per 10,000 people \\
\hline & Nurse practitioner abundance & The number of nurse practitioners per 10,000 people \\
\hline \multirow{3}{*}{ Health } & Obesity rate & Percentage of obese population (i.e., individuals whose BMI is 30 or higher) \\
\hline & Physical inactivity rate & Percentage of population not engaging in physical activity regularly \\
\hline & Smoking prevalence & $\begin{array}{l}\text { Percentage of population who smoke cigarettes regularly (i.e., have smoked at } \\
\text { least } 100 \text { cigarettes in their life and currently smoke at least one cigarette a day) }\end{array}$ \\
\hline \multirow{3}{*}{ Economic } & Income & Median household income \\
\hline & Poverty rate & Percentage of population in poverty \\
\hline & Unemployment rate & Percentage of unemployment population \\
\hline
\end{tabular}

We then tested multicollinearity across the candidate variables and finetuned the final model with variables including age, sex, race, and socioeconomic variables, unemployment rate, uninsured rate, college degree rate, obesity rate, and nurse practitioner per 10,000 people. Specifically, we excluded the variables (e.g., median household income, population density, poverty percentage, high school degree rate, physical inactivity rate, smoking prevalence, medical doctors per 10,000 people) that were highly correlated with other variables (correlation coefficient $>0.7$ ) in this step. We employed this relaxed criterion for two reasons: (1) Because we used spatial regression afterward, multicollinearity would be different after we incorporated spatial autocorrelation. (2) We intended to include as many 
variables as possible to better represent Snyder and Parks' index, so that the results could be intuitive and interpretable.

\subsection{Data Sources}

The data sources used in this work varied. The age variable was extracted from U.S. Census Population and Housing Unit Estimates, 2010-2018. Sex, race, and college degree rate were extracted from the U.S. Census Bureau, Population Estimates Program (PEP), and American Community Survey (ACS), updated 1 July 2019. The unemployment rate and poverty rate were retrieved from the U.S. Census Bureau, Small Area Income and Poverty Estimates (SAIPE) Program (2019). The uninsured rate was retrieved from the U.S. Census Bureau, Small Area Health Insurance Estimates (SAHIE) Program (2018). The obesity rate was retrieved from U.S. CDC Diabetes County Data Indicators, 2006-2017. The nurse practitioner number was retrieved from Health Resources \& Services Administration (HRSA) Area Health Resources Files, 2017 and 2018. The confirmed cases number of COVID-19 from July 2020 to December 2020 was obtained from USAFacts, which is also the data source that the U.S. CDC uses. Specifically, the case data of a certain date reflect the cumulative totals of that date [41]. Log transformation was applied in the dependent variable and the explanatory variables to normalize skewed data.

\subsection{Spatial Regression Models}

We calculated spatial weights using queen contiguity which defines neighbors by the presence of shared edges and vertices. Figure 1 shows the county map of South Carolina with the links between each neighbor (i.e., county). Spatial modeling was used to describe the relationship between the COVID-19 cases and factors at the county level. The following spatial models were used to fit our data: spatial error model (SEM), spatial lag model (SLM), conditional autoregressive (CAR) model, and GWR model. We used SEM to observe spatial autocorrelation between the residuals of neighboring counties, which incorporates spatial effects through the error term. SLM applies spatial dependence by adding a spatially lagged response variable as an additional predictor on the linear model equation. This model assumes that the COVID-19 incidence rate in one county is directly influenced by the COVID-19 incidence rates in its neighboring counties. If positive spatial lag is observed in SLM, it would suggest that COVID-19 incidence rates in neighboring counties covary. The CAR model relies on the conditional distribution of the spatial error terms and assumes the region is a function of its neighbors but not the neighbors of neighbors (i.e., first-order dependency). We used the GWR method to examine the local models, which is based on kernel-weighted regression and allows for parameters to vary spatially [42].

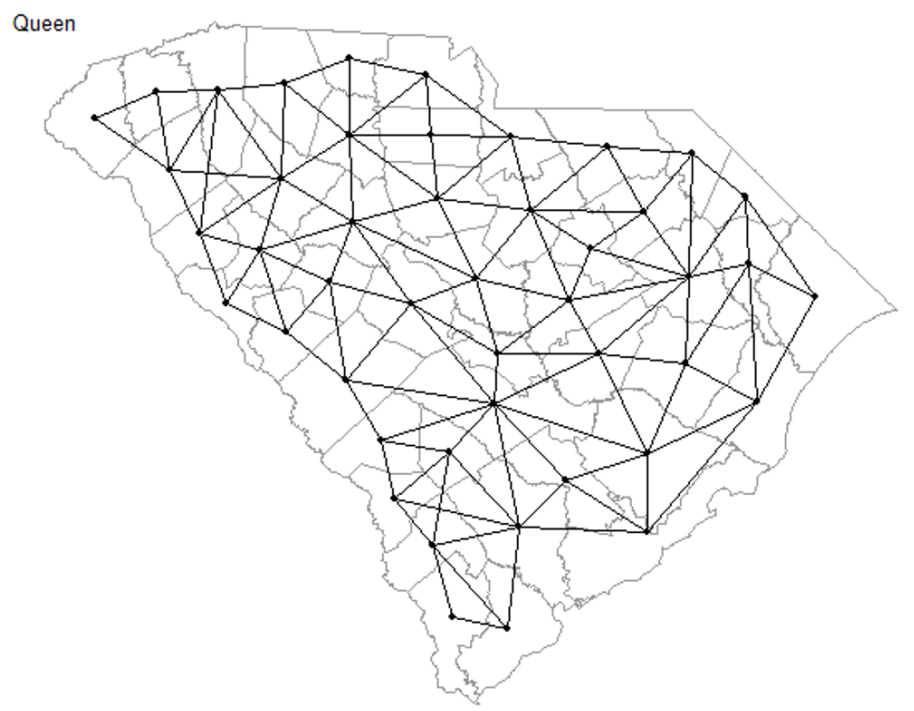

Figure 1. Contiguity Queen neighbors of counties in South Carolina. 


\section{Results}

\subsection{Distribution of COVID-19 Cases and Covariates}

After model selection, the final model contained eight explanatory variables, namely sex, race, age, college degree rate, obesity rate, unemployment rate, uninsured rate, and nursing practitioner abundance. We summarized and showed maps of distributions for all the variables in the model (Figure 2). To make the descriptive map comparison between variables easier, we held back the temporal dimension and used average COVID19 incidences per 1000 people around July 15th. In Figure 2, we observed some similarities between the distribution of COVID-19 cases and certain demographic and socioeconomic variables. For example, the maps of sex and age were congruent with the map of COVID-19 incidence rate. The map of the obesity rate showed a nearly opposite pattern compared to the map of COVID-19 cases.

COVID-19 Prevalence (07/15)

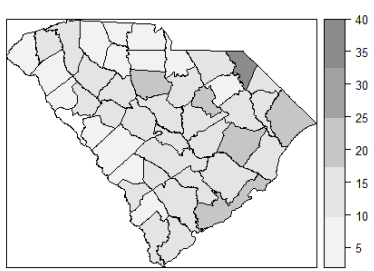

Median Age

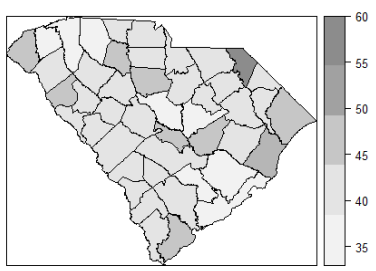

College Degree Rate

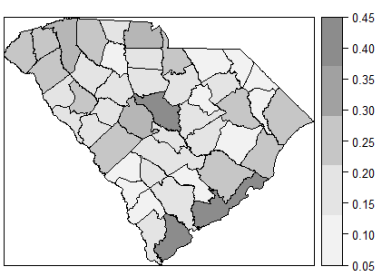

Sex (Male)

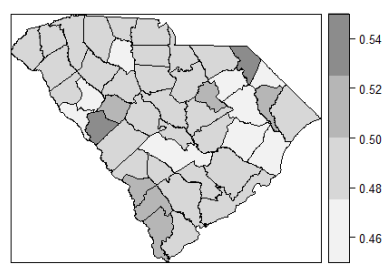

Unemployment Rate

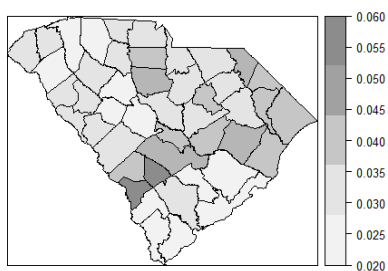

Uninsured Rate

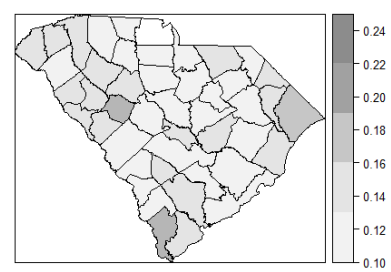

Race (White)

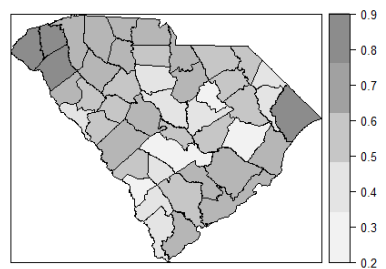

Obesity Rate

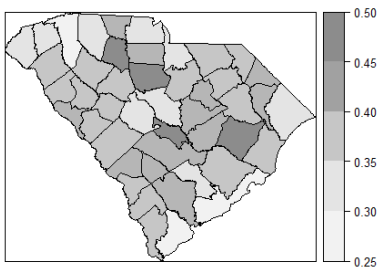

Nurse Practitioners per 10,000

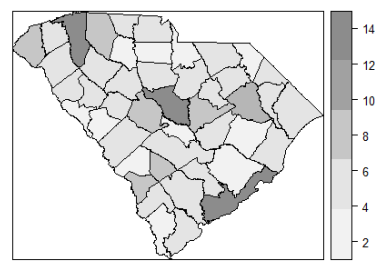

Figure 2. Distribution maps of the variables (in percentages) in the model.

\subsection{Global Models for Spatial Correlation}

When considering the temporal dimension, four geospatial models were built to examine the spatial correlation of COVID-19 incidence across the counties in South Carolina including the SEM, SLM, CAR model, and GWR model. The significant results from Moran's I test $(p$ values $<0.05)$ suggested the existence of spatial autocorrelation. We summarized the coefficients of the variables and corresponding $\mathrm{p}$ values for global models in Tables 2-4 (i.e., SEM, SLM, and CAR model). All the models were significant at 0.05 level, indicating that spatial autocorrelations did show within the error terms. The percentage of residents who were male and the unemployment rate were statistically significant $(p$ values $<0.05)$ with positive coefficients in the three global models throughout the six time windows, while other variables were not (Tables 2-4). Interestingly, the spatial correlations between COVID-19 cases and the percent of residents who were white or obese, respectively, flipped over the course of the pandemic. Earlier in the pandemic, white race was not statistically correlated with COVID-19 cases. Later in the pandemic, beginning in December, it was positively correlated with COVID-19 cases. The obesity rate was negatively correlated with COVID-19 cases as early as July but became positively 
correlated during the months October through December in SEM and CAR, yet this pattern did not show in SLM.

Table 2. Coefficients of the explanatory variables in SEM.

\begin{tabular}{|c|c|c|c|c|c|c|}
\hline & \multicolumn{2}{|c|}{ July 15} & \multicolumn{2}{|c|}{ August 15} & \multicolumn{2}{|c|}{ September 15} \\
\hline & Coef. & $p$ Value & Coef. & $p$ Value & Coef. & $p$ Value \\
\hline Male percentage & 9.26 & *0.014 & 7.72 & *0.013 & 9.65 & $* * 0.002$ \\
\hline White percentage & 0.21 & 0.970 & -0.06 & 0.910 & -0.05 & 0.966 \\
\hline Median age & -0.08 & 0.910 & 0.16 & 0.793 & 0.03 & 0.960 \\
\hline College degree rate & 0.53 & 0.273 & 0.39 & 0.313 & 0.45 & 0.228 \\
\hline Obesity rate & -2.17 & 0.198 & -0.76 & 0.589 & -0.25 & 0.846 \\
\hline Unemployment rate & 2.88 & $* * 0.003$ & 2.07 & ** 0.009 & 2.19 & $* * 0.004$ \\
\hline Uninsured rate & 1.91 & 0.052 & 0.49 & 0.539 & 0.12 & 0.875 \\
\hline \multirow[t]{3}{*}{ NP abundance } & 0.08 & 0.575 & 0.04 & 0.737 & 0.07 & 0.490 \\
\hline & \multicolumn{2}{|c|}{ October 15} & \multicolumn{2}{|c|}{ November 15} & \multicolumn{2}{|c|}{ December 15} \\
\hline & Coef. & $p$ Value & Coef. & $p$ Value & Coef. & $p$ Value \\
\hline Male percentage & 11.30 & $* * 0.000$ & 11.92 & $* * 0.000$ & 11.84 & $* * 0.000$ \\
\hline White percentage & 0.35 & 0.407 & 0.73 & 0.069 & 1.17 & $* * 0.003$ \\
\hline Median age & 0.09 & 0.855 & -0.03 & 0.952 & -0.19 & 0.694 \\
\hline College degree rate & 0.35 & 0.263 & 0.34 & 0.243 & 0.38 & 0.198 \\
\hline Obesity rate & 0.32 & 0.765 & 0.58 & 0.568 & 0.68 & 0.467 \\
\hline Unemployment rate & 2.05 & $* * 0.001$ & 2.10 & $* * 0.000$ & 2.28 & $* * 0.000$ \\
\hline Uninsured rate & -0.25 & 0.689 & -0.46 & 0.438 & -0.67 & 0.260 \\
\hline NP abundance & 0.12 & 0.160 & 0.13 & 0.111 & 0.13 & 0.106 \\
\hline
\end{tabular}

Table 3. Coefficients of the explanatory variables in SLM.

\begin{tabular}{ccccccc}
\hline & \multicolumn{2}{c}{ July 15 } & \multicolumn{2}{c}{ August 15 } & \multicolumn{2}{c}{ September 15 } \\
\cline { 2 - 7 } & Coef. & $p$ Value & Coef. & $p$ Value & Coef. & $p$ Value \\
\hline Male percentage & 10.70 & $* 0.015$ & 9.28 & $* * 0.008$ & 9.65 & ${ }^{* *} 0.002$ \\
\hline White percentage & -0.07 & 0.911 & -0.48 & 0.348 & -0.02 & 0.966 \\
\hline Median age & 0.04 & 0.962 & 0.41 & 0.537 & 0.03 & 0.960 \\
\hline College degree rate & 0.44 & 0.372 & 0.22 & 0.583 & 0.45 & 0.228 \\
\hline Obesity rate & -3.16 & 0.076 & -2.09 & 0.143 & -0.25 & 0.846 \\
\hline Unemployment rate & 2.83 & $* * 0.003$ & 1.93 & $* 0.011$ & 2.19 & $* * 0.004$ \\
\hline Uninsured rate & 1.75 & 0.081 & 0.64 & 0.419 & 0.12 & 0.875 \\
\hline NP abundance & 0.07 & 0.640 & 0.03 & 0.801 & 0.07 & 0.490 \\
\hline
\end{tabular}


Table 3. Cont.

\begin{tabular}{ccccccc}
\hline & \multicolumn{2}{c}{ October 15 } & \multicolumn{2}{c}{ November 15 } & \multicolumn{2}{c}{ December 15 } \\
\cline { 2 - 7 } & Coeff. & $p$ Value & Coeff. & $p$ Value & Coeff. & $p$ Value \\
\hline Male percentage & 12.81 & ${ }^{* *} 0.000$ & 13.30 & $* * 0.000$ & 13.16 & ${ }^{* *} 0.000$ \\
\hline White percentage & 0.18 & 0.646 & 0.66 & 0.077 & 1.21 & $* * 0.001$ \\
\hline Median age & 0.26 & 0.604 & 0.11 & 0.815 & -0.10 & 0.840 \\
\hline College degree rate & 0.15 & 0.608 & 0.14 & 0.611 & 0.19 & 0.522 \\
\hline Obesity rate & -0.86 & 0.431 & -0.52 & 0.618 & -0.16 & 0.882 \\
\hline Unemployment rate & 2.01 & $* * 0.001$ & 2.09 & $* * 0.000$ & 2.31 & $* * 0.000$ \\
\hline Uninsured rate & 0.09 & 0.882 & -0.14 & 0.815 & -0.37 & 0.528 \\
\hline NP abundance & 0.11 & 0.213 & 0.12 & 0.149 & 0.13 & 0.124 \\
\hline NP: nurse practitioner; ${ }^{*}: p<0.05 ; * * p<0.01$. & & & & &
\end{tabular}

Table 4. Coefficients of the explanatory variables in the CAR model.

\begin{tabular}{|c|c|c|c|c|c|c|}
\hline & \multicolumn{2}{|c|}{ July 15} & \multicolumn{2}{|c|}{ August 15} & \multicolumn{2}{|c|}{ September 15} \\
\hline & Coef. & $p$ Value & Coef. & $p$ Value & Coef. & $p$ Value \\
\hline Male percentage & 9.59 & *0.012 & 8.10 & $* * 0.009$ & 9.97 & $* * 0.001$ \\
\hline White percentage & 0.08 & 0.901 & -0.10 & 0.849 & 0.01 & 0.988 \\
\hline Median age & -0.04 & 0.953 & 0.23 & 0.700 & 0.07 & 0.908 \\
\hline College degree rate & 0.32 & 0.500 & 0.00 & 0.568 & 0.30 & 0.422 \\
\hline Obesity rate & -3.13 & 0.065 & -1.61 & 0.242 & -1.09 & 0.402 \\
\hline Unemployment rate & 2.82 & $* * 0.002$ & 1.99 & ** 0.008 & 2.17 & $* * 0.003$ \\
\hline Uninsured rate & 2.16 & * 0.026 & 0.79 & 0.317 & 0.43 & 0.568 \\
\hline \multirow[t]{3}{*}{ NP abundance } & 0.08 & 0.565 & 0.03 & 0.784 & 0.05 & 0.613 \\
\hline & \multicolumn{2}{|c|}{ October 15} & \multicolumn{2}{|c|}{ November 15} & \multicolumn{2}{|c|}{ December 15} \\
\hline & Coeff. & $p$ Value & Coeff. & $p$ Value & Coeff. & $p$ Value \\
\hline Male percentage & 11.39 & ** 0.000 & 12.01 & $* * 0.000$ & 11.97 & $* * 0.000$ \\
\hline White percentage & 0.33 & 0.445 & 0.71 & 0.079 & 1.18 & $* * 0.003$ \\
\hline Median age & 0.12 & 0.813 & 0.00 & 0.996 & -0.17 & 0.727 \\
\hline College degree rate & 0.33 & 0.299 & 0.32 & 0.275 & 0.35 & 0.228 \\
\hline Obesity rate & 0.24 & 0.821 & 0.53 & 0.598 & 0.66 & 0.512 \\
\hline Unemployment rate & 2.02 & $* * 0.001$ & 2.07 & $* * 0.000$ & 2.27 & $* * 0.000$ \\
\hline Uninsured rate & -0.22 & 0.728 & -0.44 & 0.461 & -0.64 & 0.279 \\
\hline NP abundance & 0.13 & 0.146 & 0.13 & 0.096 & 0.14 & 0.091 \\
\hline
\end{tabular}

\subsection{Local Models for Spatial Correlation}

The results of the GWR model are summarized in Table 5. In the GWR models, the calculated bandwidths were $60.87 \mathrm{~km}$ for July 15 and $154.41 \mathrm{~km}$ for the rest of the time points. Taking July 15 as an example, the GWR model possessed the lowest Akaike Information Criterion (AIC) value of 51.24, compared to the global models such as SEM $($ AIC $=61.59)$, SLM $($ AIC $=58.72)$, and the CAR model (AIC = 59.39) (Table 6). A smaller AIC indicates a better fit when compared with other models that were built on the same data. These two findings collectively suggest highly localized spatial correlations at the beginning of the pandemic, yet this effect started to decline as the pandemic evolved. Figure 3 shows the geographic distribution of local coefficient estimates of GWR models for 
COVID-19 incidence rate associated with each explanatory variable. For each explanatory variable, we can observe a clear trend suggesting that the heterogeneity among coefficients became homogeneity throughout the time.

Table 5. Summary of the results from the GWR model fitting.

\begin{tabular}{|c|c|c|c|c|c|}
\hline \multicolumn{6}{|c|}{ July 15th } \\
\hline Covariates & Min. & Q1. & Median & Q3 & Max. \\
\hline Male percentage & 6.73 & 7.68 & 8.11 & 8.50 & 8.98 \\
\hline White percentage & -0.59 & -0.36 & -0.20 & -0.02 & 0.21 \\
\hline Median age & -0.67 & -0.15 & 0.09 & 0.34 & 0.71 \\
\hline College degree rate & 0.64 & 0.71 & 0.75 & 0.80 & 0.83 \\
\hline Obesity rate & -0.81 & -0.49 & -0.32 & -0.10 & 0.22 \\
\hline Unemployment rate & 1.82 & 2.15 & 2.36 & 2.66 & 3.18 \\
\hline Uninsured rate & 0.48 & 0.76 & 0.93 & 1.20 & 1.58 \\
\hline NP abundance & 0.17 & 0.20 & 0.21 & 0.23 & 0.24 \\
\hline \multicolumn{6}{|c|}{ August 15th } \\
\hline Covariates & Min. & Q1. & Median & Q3 & Max. \\
\hline Male percentage & 7.11 & 7.33 & 7.44 & 7.60 & 7.85 \\
\hline White percentage & -0.67 & -0.65 & -0.63 & -0.61 & -0.59 \\
\hline Median age & 0.32 & 0.41 & 0.44 & 0.50 & 0.57 \\
\hline College degree rate & 0.48 & 0.49 & 0.49 & 0.50 & 0.50 \\
\hline Obesity rate & -0.06 & -0.05 & -0.03 & -0.01 & 0.02 \\
\hline Unemployment rate & 1.57 & 1.64 & 1.69 & 1.75 & 1.85 \\
\hline Uninsured rate & -0.05 & -0.01 & 0.01 & 0.05 & 0.10 \\
\hline NP abundance & 0.12 & 0.12 & 0.12 & 0.12 & 0.13 \\
\hline \multicolumn{6}{|c|}{ September 15th } \\
\hline Covariates & Min. & Q1. & Median & Q3 & Max. \\
\hline Male percentage & 9.28 & 9.44 & 9.55 & 9.69 & 9.90 \\
\hline White percentage & -0.43 & -0.38 & -0.37 & -0.35 & -0.33 \\
\hline Median age & 0.20 & 0.28 & 0.31 & 0.36 & 0.43 \\
\hline College degree rate & 0.42 & 0.43 & 0.44 & 0.44 & 0.45 \\
\hline Obesity rate & -0.07 & -0.05 & -0.04 & -0.02 & 0.01 \\
\hline Unemployment rate & 1.77 & 1.83 & 1.87 & 1.93 & 2.02 \\
\hline Uninsured rate & -0.22 & -0.17 & -0.14 & -0.11 & -0.05 \\
\hline NP abundance & 0.12 & 0.12 & 0.13 & 0.13 & 0.13 \\
\hline \multicolumn{6}{|c|}{ October 15th } \\
\hline Covariates & Min. & Q1. & Median & Q3 & Max. \\
\hline Male percentage & 11.37 & 11.58 & 11.69 & 11.82 & 12.05 \\
\hline White percentage & 0.07 & 0.11 & 0.13 & 015 & 0.17 \\
\hline Median age & 0.20 & 0.24 & 0.27 & 0.29 & 0.35 \\
\hline College degree rate & 0.30 & 0.31 & 0.32 & 0.33 & 0.33 \\
\hline Obesity rate & 0.29 & 0.31 & 0.33 & 0.36 & 0.39 \\
\hline Unemployment rate & 1.81 & 1.86 & 1.89 & 1.94 & 2.00 \\
\hline Uninsured rate & -0.31 & -0.27 & -0.25 & -0.22 & -0.17 \\
\hline NP abundance & 0.16 & 0.16 & 0.16 & 0.16 & 0.17 \\
\hline
\end{tabular}


Table 5. Cont.

\begin{tabular}{|c|c|c|c|c|c|}
\hline \multicolumn{6}{|c|}{ November 15th } \\
\hline Covariates & Min. & Q1. & Median & Q3 & Max. \\
\hline Male percentage & 11.96 & 12.15 & 12.24 & 12.37 & 12.57 \\
\hline White percentage & 0.57 & 0.60 & 0.63 & 0.65 & 0.68 \\
\hline Median age & 0.03 & 0.08 & 0.11 & 0.14 & 0.20 \\
\hline College degree rate & 0.27 & 0.28 & 0.29 & 0.30 & 0.30 \\
\hline Obesity rate & 0.53 & 0.55 & 0.57 & 0.59 & 0.64 \\
\hline Unemployment rate & 1.91 & 1.95 & 1.98 & 2.03 & 2.09 \\
\hline Uninsured rate & -0.51 & -0.47 & -0.45 & -0.43 & -0.39 \\
\hline NP abundance & 0.16 & 0.17 & 0.17 & 0.17 & 0.17 \\
\hline \multicolumn{6}{|c|}{ December 15th } \\
\hline Covariates & Min. & Q1. & Median & Q3 & Max. \\
\hline Male percentage & 12.03 & 12.19 & 12.29 & 12.43 & 12.62 \\
\hline White percentage & 1.14 & 1.18 & 1.21 & 1.23 & 1.27 \\
\hline Median age & -0.18 & -0.13 & -0.10 & -0.07 & -0.02 \\
\hline College degree rate & 0.28 & 0.29 & 0.30 & 0.31 & 0.32 \\
\hline Obesity rate & 0.68 & 0.70 & 0.72 & 0.74 & 0.79 \\
\hline Unemployment rate & 2.16 & 2.20 & 2.23 & 2.27 & 2.33 \\
\hline Uninsured rate & -0.69 & -0.65 & -0.63 & -0.60 & -0.57 \\
\hline NP abundance & 0.16 & 0.17 & 0.17 & 0.17 & 0.17 \\
\hline
\end{tabular}

NP: nurse practitioner.

Table 6. Summary of models' AIC values over time.

\begin{tabular}{ccccc}
\hline & SEM & SLM & CAR & GWR \\
\hline July 15 & 61.59 & 58.72 & 59.39 & 51.24 \\
\hline August 15 & 41.47 & 36.64 & 39.81 & 34.49 \\
\hline September 15 & 35.62 & 30.67 & 35.20 & 25.64 \\
\hline October 15 & 17.00 & 11.96 & 17.42 & 5.31 \\
\hline November 15 & 11.52 & 6.68 & 11.94 & -0.54 \\
\hline December 15 & 10.74 & 8.31 & 11.13 & -1.48 \\
\hline
\end{tabular}


Male Percentage

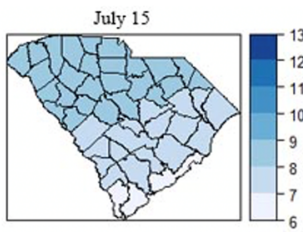

September 15

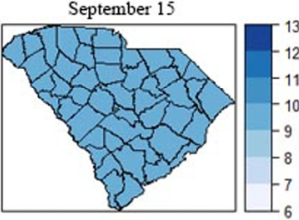

November 15
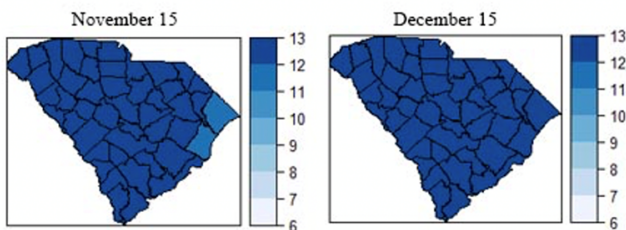

Median Age
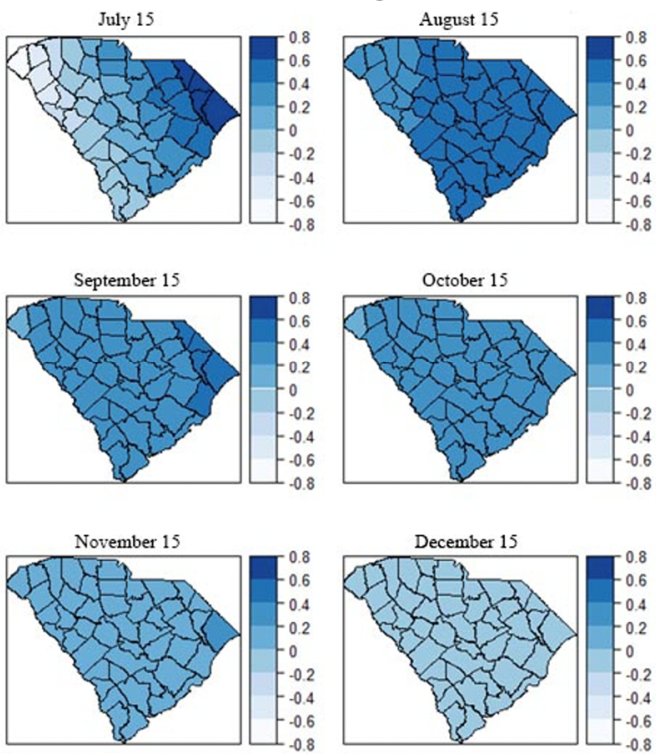

White Percentage
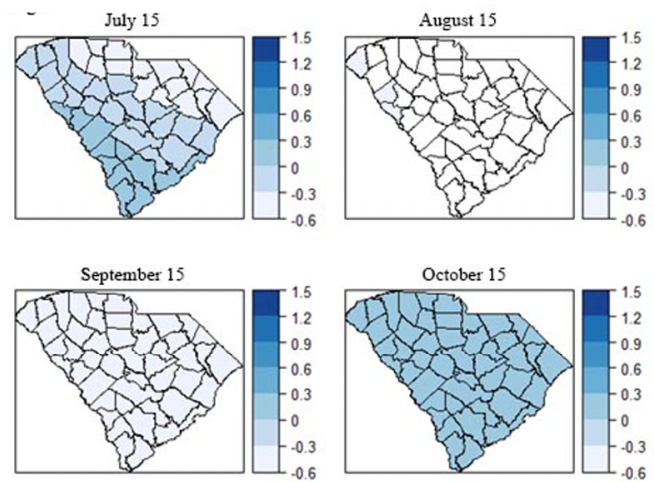

November 15
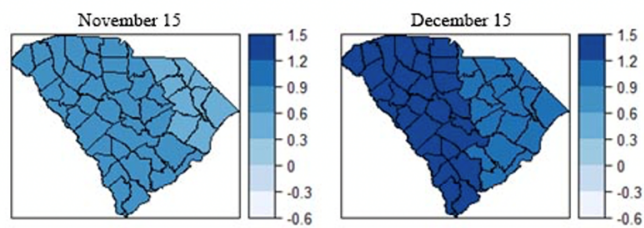

College Degree Rate
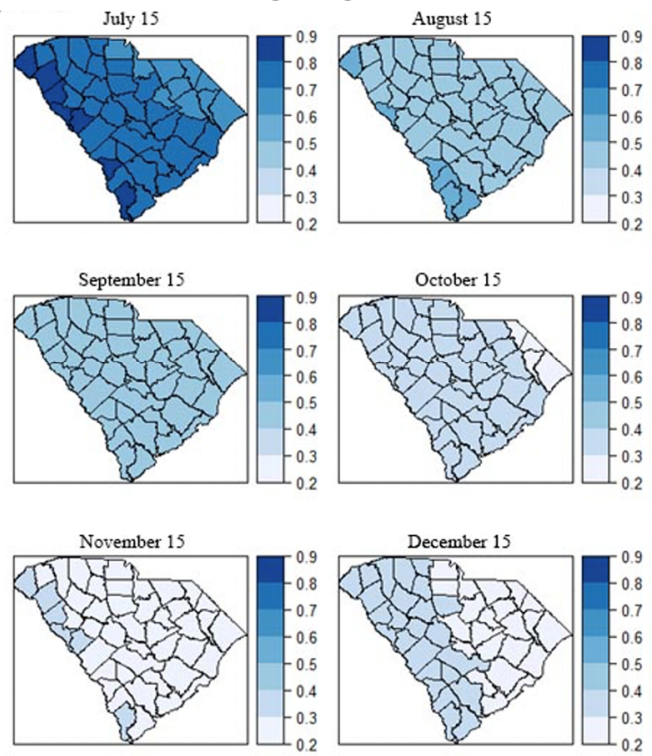

Figure 3. Cont. 


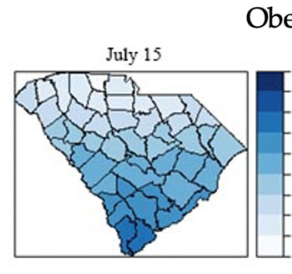

Obesity Rate

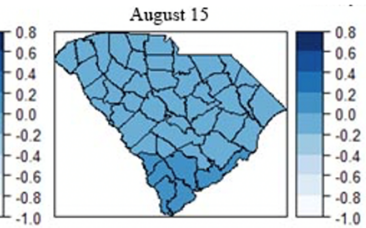

September 15
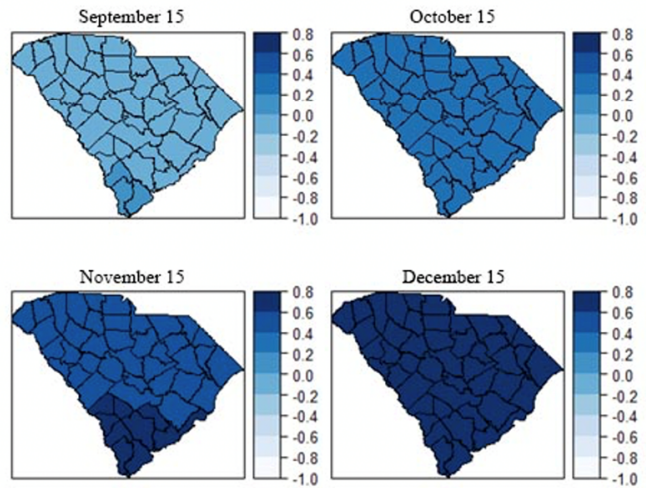

Uninsured Rate

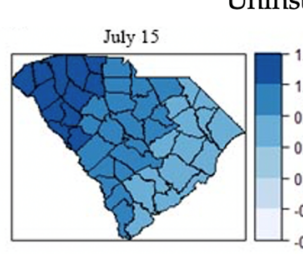

September 15
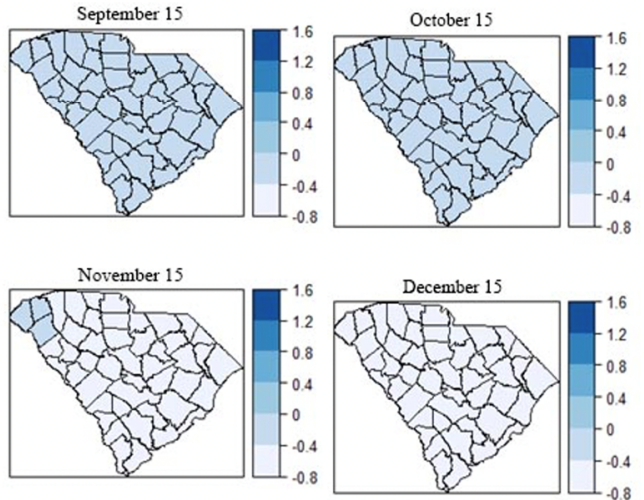
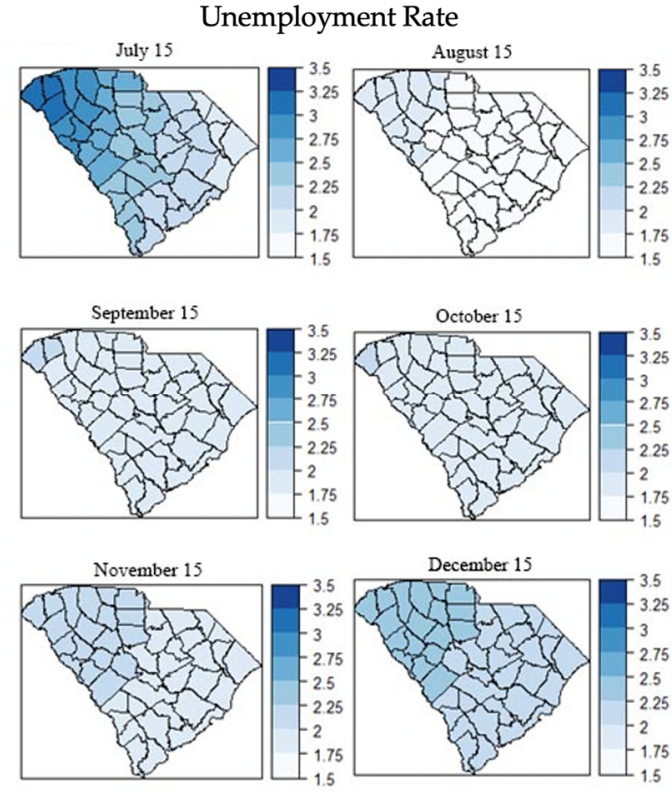

Nurse Practitioner per 10,000 people
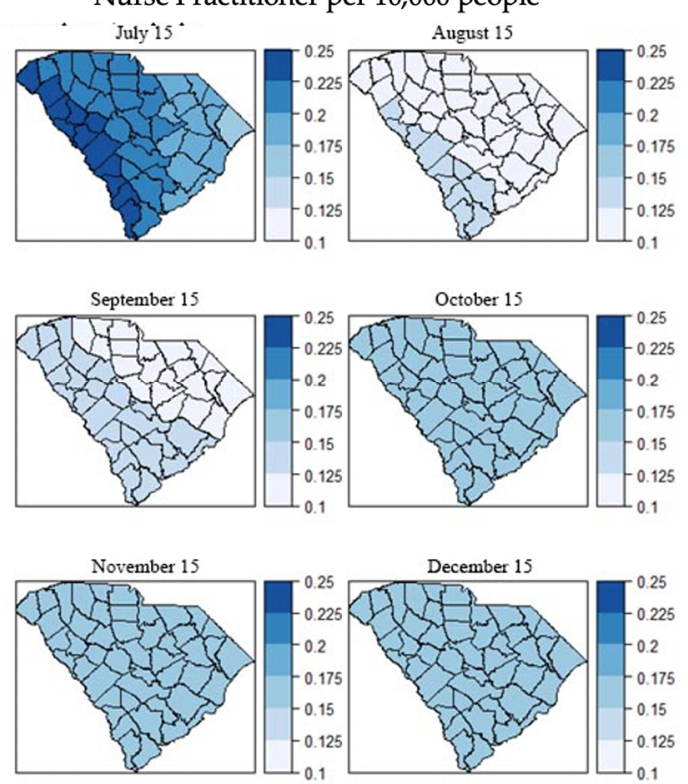

Figure 3. Monthly geographic distribution of local coefficient estimates of GWR models for COVID19 incidence rate associated with the explanatory variables between 15 July 2020 and 15 December 2020.

\section{Discussion}

In this geospatial study, we adopted the socioecological vulnerability index from Snyder and Parks and compiled 15 variables within four categories of the index which could potentially explain the geographic patterns of COVID-19 transmission in SC [39]. Our study resulted in three principal findings. First, our study demonstrated the spatial autocorrelations of COVID-19 incidence at the county level in SC. The results from global models and local models were consistent with the initial observation of the distribution maps of covariates. Second, some PIDRs (e.g., male percentage, unemployment rate) had consistent spatial correlations with COVID-19 incidence over time while some other PIDRs (e.g., percentage of the white population, obesity rate) showed divergent spatial correlations at different times of the pandemic, suggesting a critical role of the temporal dimension in the geospatial epidemiology of COVID-19 transmission. Third, the geospatial 
effect of PIDRs was strong at the beginning of the pandemic and started to decline as the infection cases continued to surge, suggesting the importance of early identification of critical PIDRs and timely intervention for possible future outbreaks of infectious diseases.

Aligned with existing studies [28,30], two PIDRs (e.g., male percentage and unemployment rate) were found to be significantly associated with a higher risk of COVID-19 infection in global models (e.g., SEM, SLM, and CAR). The higher risk of COVID-19 infection among the male population can be explained by several sex-related factors [43]. Genetically, males have a higher expression of angiotensin-converting enzyme-2 (ACE2), which could be the receptor for SARS-CoV-2 [44,45]. The immunological response of SARCoV-2 may be different between males and females [46,47]. In addition, females have been found to have a more responsible attitude of health behaviors towards COVID-19 than males [19,48]. A higher unemployment rate reflects a higher socioeconomic vulnerability of COVID-19 infection. People with the ability to work from home are less likely to be infected because of higher job security $[49,50]$. Interestingly, our results are different from an existing study from Johnson et al. [51]. They found unemployment to be a protective feature of COVID-19 infection and argued that it might be related to the lack of transportation among the unemployed. The role of unemployment in COVID-19 transmission needs further investigation.

We found that the white population was not statistically correlated with COVID-19 incidence from July to October and became positively correlated with COVID-19 incidence (all $p<0.01$ for SEM, SLM, CAR) in December. To the best of our knowledge, this finding has not been previously reported. We suspect that this finding is related to the fact that the COVID-19 incidence rate was higher in large metropolitan areas (e.g., urban, suburban) early on in the pandemic (i.e., March-May 2020) and diffused to small and nonmetropolitan areas, where proportions of white people are higher, later [31]. Among the 26 counties that are classified as metropolitan areas in South Carolina, only three have a white population of less than $50 \%$, and five have a white population of less than $60 \%$ [52,53]. Previous studies found that racial minorities had a higher risk of COVID-19 infection [28,30,33], but these findings have not been tested or interpreted by the temporal dimension of the pandemic. Cunningham and Wigfall reported that racial attitudes towards COVID-19 had a significant impact on the likelihood of infection and mitigated the effect of racial difference, which also could explain our finding [54]. In addition, our result could be related to the finding that a higher proportion of white people took COVID-19 tests than other races in the latter months [55]. Median age, college degree rate, obesity rate, uninsured rate, and NP abundance were not statistically correlated with the COVID-19 infection rate.

Our findings suggest that early measures could be related to the transmission of COVID-19 since the geographic differences in COVID-19 infection reduced over time, indicated by the decreasing AIC values across models longitudinally (Table 6). The decrease in AICs of local model (i.e., GWR model) over time indicated the persistence of the nonstationary spatial autocorrelation. Although the GWR models have lower AIC values compared with the global models, the coefficients of the variables in GWR models did not vary substantially, indicating small nonstationary effects. The small ranges of the coefficients geographically could be related to the insufficient granularity of the county-level data considering the study sample of South Carolina. Nevertheless, it is very interesting that the regional variances were decreasing over time within the study time frame.

This study is among the first to examine geospatial patterns in COVID-19 infection as well as PIDRs. Most studies have focused on patients with different levels of severity with COVID-19, which limits opportunities for examining possible disparities and PIDRs in COVID-19 infection [56]. For example, older adults, people with certain medical conditions, and pregnant women were found to be associated with a higher risk of severe illnesses of COVID-19, while our study found that the male population and unemployment rate were risk factors of COVID-19 infection [56]. Intuitively, the PIDR set for severe illnesses of COVID-19 is related to the physical condition of patients and the PIDR set for COVID-19 infection is jointly influenced by demographic and socioeconomic factors. Compared with 
PIDRs for severe illnesses, PIDRs for infection are highly sensitive to geographic regions and temporal dynamics of the pandemic because the transmission of COVID-19 is related to the activity of people. PIDRs for COVID-19 infection provide important information for developing interventions on targeted populations who share the same PIDRs at the beginning of the pandemic, which is imperative for containing the early-stage transmission and potential consequences in future infectious disease outbreaks.

Our study has several limitations. First, we did not use longitudinal measures of PIDRs due to limited surveillance data. Second, we used reported cases as a measure of COVID-19 prevalence. This measure could be potentially biased because testing rate and test positivity were not considered due to unavailable surveillance data. For example, data for COVID-19 testing rates for each race were not available for examining the racial differences [57-59]. Third, due to the limited data access, we used county-level data in this study whereas using zip code-level data would have offered a better granularity of data in the statistical models. Fourth, mobility patterns have been identified as an important factor for COVID-19 transmission, which is not accounted for due to the limited data availability [60]. Fifth, our methodology does not include the contrast between restrictions and temporary spatial patterns. Thus, implications resulted from temporal patterns should be discussed with caution. At last, variables used in this study may not be exhaustive in terms of all possible contributing factors of COVID-19 infection as this work is based on the framework from Snyder and Parks. Future studies could integrate variables such as the Social Vulnerability Index (SVI) for exploring the negative effects in communities towards hazardous events [61-63].

\section{Conclusions}

Our study found that the geospatial distribution of COVID-19 incidence was constantly influenced by several key PIDRs including male percentage and unemployment. PIRDs such as white percentage and obesity rate were negatively correlated with COVID-19 incidence at the beginning of the pandemic and then became positively correlated with COVID-19 incidence. These identified PIDRs are different from those found to be associated with poor clinical outcomes (e.g., severity and mortality) of patients who are engaged with medical care. Our study found disparities in COVID-19 transmission and suggested newly identified temporal dynamics in specific PIDRs such as white percentage and obesity rate. These findings are subject to biases caused by limited data access and should be considered provisional guidelines to the temporal geospatial epidemiology of COVID-19 transmission and underlying PIDRs of the pandemic in South Carolina.

Author Contributions: Conceptualization, T.L., N.H., N.Y. and C.L.; methodology, T.L., N.Y., Z.L. and C.L.; software, T.L., N.Y.; validation, T.L. and C.L.; formal Analysis, T.L.; investigation, T.L., N.H. and C.L.; resources, C.L.; data curation, T.L. and N.Y.; writing-original draft preparation, T.L.; writing-review and editing, T.L., N.H., S.Q., C.L. and X.L.; visualization, T.L.; supervision, C.L. and X.L.; project administration, C.L.; funding acquisition, C.L. All authors have read and agreed to the published version of the manuscript.

Funding: Research reported in this publication was supported by NIAID of the National Institutes of Health under award number R01AI127203-05S1. The content is solely the responsibility of the authors and does not necessarily represent the official views of the National Institutes of Health. Research reported in this publication was also supported by a seed grant from the University of South Carolina Arnold School of Public Health.

Institutional Review Board Statement: This study was reviewed by the Office of Research Compliance, an administrative office that supports the University of South Carolina Institutional Review Board (USC IRB). The Office of Research Compliance, on behalf of the USC IRB, has determined that the referenced study meets the Not Human Subject criteria.

Informed Consent Statement: Not applicable.

Data Availability Statement: The data presented in this study are available on request from the corresponding author. 
Conflicts of Interest: The authors declare no conflict of interest.

\section{References}

1. Ahmad, F.B.; Cisewski, J.A.; Miniño, A.; Anderson, R.N.J.M. Provisional mortality data-United States, 2020. Morb. Mortal. Wkly. Rep. 2021, 70, 519. [CrossRef]

2. USAFacts South Carolina Coronavirus Cases and Deaths. Available online: https://usafacts.org/visualizations/coronaviruscovid-19-spread-map/state/south-carolina (accessed on 29 January 2021).

3. USAFacts US Coronavirus Cases and Deaths. Available online: https://usafacts.org/visualizations/coronavirus-covid-19 -spread-map/ (accessed on 29 January 2021).

4. BEA Gross Domestic Product, 4th Quarter and Year 2020 (Advance Estimate). Available online: https://www.bea.gov/news/20 21/gross-domestic-product-4th-quarter-and-year-2020-advance-estimate (accessed on 30 January 2021).

5. Walmsley, T.; Rose, A.; Wei, D. The Impacts of the Coronavirus on the Economy of the United States. Econ. Disasters Clim. Chang. 2021, 5, 1-52. [CrossRef]

6. Dangermond, J.; De Vito, C.; Pesaresi, C.J.J. Using GIS in the Time of the COVID-19 Crisis, casting a glance at the future. A joint discussion. J-READING J. Res. Didat. Geogr. 2020, 1, 195-205.

7. Chen, T.; Wu, D.; Chen, H.; Yan, W.; Yang, D.; Chen, G.; Ma, K.; Xu, D.; Yu, H.; Wang, H.; et al. Clinical characteristics of 113 deceased patients with coronavirus disease 2019: Retrospective study. BMJ 2020, 368, m1091. [CrossRef] [PubMed]

8. Li, X.; Xu, S.; Yu, M.; Wang, K.; Tao, Y.; Zhou, Y.; Shi, J.; Zhou, M.; Wu, B.; Yang, Z.; et al. Risk factors for severity and mortality in adult COVID-19 inpatients in Wuhan. J. Allergy Clin. Immunol. 2020, 146, 110-118. [CrossRef] [PubMed]

9. Williamson, E.J.; Walker, A.J.; Bhaskaran, K.; Bacon, S.; Bates, C.; Morton, C.E.; Curtis, H.J.; Mehrkar, A.; Evans, D.; Inglesby, P.; et al. Factors associated with COVID-19-related death using OpenSAFELY. Nature 2020, 584, 430-436. [CrossRef] [PubMed]

10. Wu, Z.; McGoogan, J.M. Characteristics of and Important Lessons from the Coronavirus Disease 2019 (COVID-19) Outbreak in China: Summary of a Report of 72314 Cases from the Chinese Center for Disease Control and Prevention. JAMA 2020, 323, 1239-1242. [CrossRef] [PubMed]

11. Zhou, F.; Yu, T.; Du, R.; Fan, G.; Liu, Y.; Liu, Z.; Xiang, J.; Wang, Y.; Song, B.; Gu, X.; et al. Clinical course and risk factors for mortality of adult inpatients with COVID-19 in Wuhan, China: A retrospective cohort study. Lancet 2020, 395, $1054-1062$. [CrossRef]

12. Price-Haywood, E.G.; Burton, J.; Fort, D.; Seoane, L. Hospitalization and Mortality among Black Patients and White Patients with Covid-19. N. Engl. J. Med. 2020, 382, 2534-2543. [CrossRef]

13. Park, J.J.; Decloedt, E.H.; Rayner, C.R.; Cotton, M.; Mills, E.J. Clinical trials of disease stages in COVID 19: Complicated and often misinterpreted. Lancet Glob. Health 2020, 8, e1249-e1250. [CrossRef]

14. Paul, A.; Englert, P.; Varga, M. Socio-economic disparities and COVID-19 in the USA. medRxiv 2020, 2. [CrossRef]

15. de Lusignan, S.; Dorward, J.; Correa, A.; Jones, N.; Akinyemi, O.; Amirthalingam, G.; Andrews, N.; Byford, R.; Dabrera, G.; Elliot, A.; et al. Risk factors for SARS-CoV-2 among patients in the Oxford Royal College of General Practitioners Research and Surveillance Centre primary care network: A cross-sectional study. Lancet Infect. Dis. 2020, 20, 1034-1042. [CrossRef]

16. Hawkins, R.B.; Charles, E.J.; Mehaffey, J.H. Socio-economic status and COVID-19-related cases and fatalities. Public Health 2020, 189, 129-134. [CrossRef] [PubMed]

17. Lewis, N.M.; Friedrichs, M.; Wagstaff, S.; Sage, K.; LaCross, N.; Bui, D.; McCaffrey, K.; Barbeau, B.; George, A.; Rose, C.J.M.; et al. Disparities in COVID-19 incidence, hospitalizations, and testing, by area-level deprivation-Utah, March 3-July 9 2020. Morb. Mortal. Wkly. Rep. 2020, 69, 1369. [CrossRef] [PubMed]

18. Papageorge, N.W.; Zahn, M.V.; Belot, M.; van den Broek-Altenburg, E.; Choi, S.; Jamison, J.C.; Tripodi, E. Socio-demographic factors associated with self-protecting behavior during the Covid-19 pandemic. J. Popul. Econ. 2021, 34, 691-738. [CrossRef] [PubMed]

19. Zhang, M.; Li, Q.; Du, X.; Zuo, D.; Ding, Y.; Tan, X.; Liu, Q. Health Behavior Toward COVID-19: The Role of Demographic Factors, Knowledge, and Attitude Among Chinese College Students During the Quarantine Period. Asia Pac. J. Public Health 2020, 32, 533-535. [CrossRef] [PubMed]

20. NIH Research Opportunity Announcement OTA-21-015B: Post-Acute Sequelae of SARS-CoV-2 Infection Initiative: SARS-CoV-2 Recovery Cohort Studies. Available online: https:/ / covid19.nih.gov/sites/default/files/2021-02/PASC-ROA-OTA-RecoveryCohort-Studies.pdf (accessed on 15 July 2021).

21. Waltenburg, M.A.; Victoroff, T.; Rose, C.E.; Butterfield, M.; Jervis, R.H.; Fedak, K.M.; Gabel, J.A.; Feldpausch, A.; Dunne, E.M.; Austin, C.J.M.; et al. Update: COVID-19 among workers in meat and poultry processing facilities-United States, April-May 2020. Morb. Mortal. Wkly. Rep. 2020, 69, 887. [CrossRef] [PubMed]

22. Al-Aly, Z.; Xie, Y.; Bowe, B. High-dimensional characterization of post-acute sequelae of COVID-19. Nature 2021, 594, 259-264. [CrossRef]

23. Deer, R.R.; Rock, M.A.; Vasilevsky, N.; Carmody, L.; Rando, H.; Anzalone, A.J.; Callahan, T.J.; Bramante, C.T.; Chute, C.G.; Greene, C.S.; et al. Characterizing Long COVID: Deep Phenotype of a Complex Condition. medRxiv 2021. [CrossRef]

24. Ostfeld, R.S.; Glass, G.E.; Keesing, F. Spatial epidemiology: An emerging (or re-emerging) discipline. Trends Ecol. Evol. 2005, 20, 328-336. [CrossRef] 
25. Baker, S.; Holt, K.E.; Clements, A.C.A.; Karkey, A.; Arjyal, A.; Boni, M.F.; Dongol, S.; Hammond, N.; Koirala, S.; Duy, P.T.; et al. Combined high-resolution genotyping and geospatial analysis reveals modes of endemic urban typhoid fever transmission. Open Biol. 2011, 1, 110008. [CrossRef] [PubMed]

26. Linard, C.; Tatem, A.J. Large-scale spatial population databases in infectious disease research. Int. J. Health Geogr. 2012, 11, 1-13. [CrossRef] [PubMed]

27. Tatem, A.J.; Adamo, S.; Bharti, N.; Burgert, C.R.; Castro, M.; Dorelien, A.; Fink, G.; Linard, C.; John, M.; Montana, L.; et al. Mapping populations at risk: Improving spatial demographic data for infectious disease modeling and metric derivation. Popul. Health Metr. 2012, 10, 8. [CrossRef] [PubMed]

28. Biggs, E.N.; Maloney, P.M.; Rung, A.L.; Peters, E.S.; Robinson, W.T. The Relationship between Social Vulnerability and COVID-19 Incidence among Louisiana Census Tracts. Front. Public Health 2021, 8, 1048. [CrossRef]

29. Fortaleza, C.M.C.B.; Guimarães, R.B.; de Almeida, G.B.; Pronunciate, M.; Ferreira, C.P. Taking the inner route: Spatial and demographic factors affecting vulnerability to COVID-19 among 604 cities from inner São Paulo State, Brazil. Epidemiol. Infect. 2020, 148, e118. [CrossRef] [PubMed]

30. Turner, N.A.; Pan, W.; Martinez-Bianchi, V.S.; Panayotti, G.M.M.; Planey, A.M.; Woods, C.W.; Lantos, P.M. Racial, Ethnic, and Geographic Disparities in Novel Coronavirus (Severe Acute Respiratory Syndrome Coronavirus 2) Test Positivity in North Carolina. Open Forum Infect. Dis. 2020, 8, ofaa413. [CrossRef]

31. Zhang, C.H.; Schwartz, G.G. Spatial Disparities in Coronavirus Incidence and Mortality in the United States: An Ecological Analysis as of May 2020. J. Rural. Health 2020, 36, 433-445. [CrossRef]

32. Martins-Filho, P.R. Relationship between population density and COVID-19 incidence and mortality estimates: A county-level analysis. J. Infect. Public Health 2021, 14, 1087-1088. [CrossRef]

33. Mollalo, A.; Vahedi, B.; Rivera, K.M. GIS-based spatial modeling of COVID-19 incidence rate in the continental United States. Sci. Total. Environ. 2020, 728, 138884. [CrossRef]

34. Qiu, Y.; Chen, X.; Shi, W. Impacts of social and economic factors on the transmission of coronavirus disease 2019 (COVID-19) in China. J. Popul. Econ. 2020, 33, 1127-1172. [CrossRef]

35. Sannigrahi, S.; Pilla, F.; Basu, B.; Basu, A.S.; Molter, A. Examining the association between socio-demographic composition and COVID-19 fatalities in the European region using spatial regression approach. Sustain. Cities Soc. 2020, 62, 102418. [CrossRef] [PubMed]

36. Mintzer, A.; Mallory, L. FULL LIST: Face Mask Ordinances in Place across SC. WIS NEWS. 2020. Available online: https: //www.wistv.com/2020/07/08/full-list-face-mask-ordinances-place-across-sc/ (accessed on 13 September 2021).

37. CDC People at Increased Risk. Available online: https://www.cdc.gov/coronavirus/2019-ncov/need-extra-precautions/index. html (accessed on 26 January 2021).

38. Cutter, S.L. Vulnerability to environmental hazards. Prog. Hum. Geogr. 1996, 20, 529-539. [CrossRef]

39. Snyder, B.F.; Parks, V. Spatial variation in socio-ecological vulnerability to Covid-19 in the contiguous United States. Health Place 2020, 66, 102471. [CrossRef] [PubMed]

40. Wisner, B.; Blaikie, P.; Blaikie, P.M.; Cannon, T.; Davis, I. At Risk: Natural Hazards, People's Vulnerability and Disasters; Psychology Press: New York, NY, USA, 2004.

41. USAFacts Detailed Methodology and Sources: COVID-19 Data. Available online: https://usafacts.org/articles/detailedmethodology-covid-19-data/ (accessed on 28 August 2021).

42. Brunsdon, C.; Fotheringham, S.; Charlton, M. Geographically Weighted Regression. J. R. Stat. Soc. Ser. D 1998, 47, 431-443. [CrossRef]

43. Bwire, G.M. Coronavirus: Why Men are More Vulnerable to Covid-19 than Women? SN Compr. Clin. Med. 2020, 2, 874-876. [CrossRef]

44. Li, G.; He, X.; Zhang, L.; Ran, Q.; Wang, J.; Xiong, A.; Wu, D.; Chen, F.; Sun, J.; Chang, C. Assessing ACE2 expression patterns in lung tissues in the pathogenesis of COVID-19. J. Autoimmun. 2020, 112, 102463. [CrossRef]

45. Zhao, Y.; Zhao, Z.; Wang, Y.; Zhou, Y.; Ma, Y.; Zuo, W. Single-Cell RNA Expression Profiling of ACE2, the Receptor of SARS-CoV-2. Am. J. Respir. Crit. Care Med. 2020, 202, 756-759. [CrossRef]

46. Ghazeeri, G.; Abdullah, L.; Abbas, O. Immunological differences in women compared with men: Overview and contributing factors. Am. J. Reprod. Immunol. 2011, 66, 163-169. [CrossRef]

47. Klein, S.L.; Flanagan, K.L. Sex differences in immune responses. Nat. Rev. Immunol. 2016, 16, 626-638. [CrossRef]

48. de la Vega, R.; Ruíz-Barquín, R.; Boros, S.; Szabo, A. Could attitudes toward COVID-19 in Spain render men more vulnerable than women? Glob. Public Health 2020, 15, 1278-1291. [CrossRef]

49. Selden, T.M.; Berdahl, T.A. COVID-19 and Racial/Ethnic Disparities In Health Risk, Employment, And Household Composition. Health Aff. 2020, 39, 1624-1632. [CrossRef]

50. Moehring, K.; Weiland, A.; Reifenscheid, M.; Naumann, E.; Wenz, A.; Rettig, T.; Krieger, U.; Fikel, M.; Cornesse, C.; Blom, A.G. Inequality in Employment Trajectories and Their Socio-Economic Consequences during the Early Phase of the COVID-19 Pandemic in Germany. SocArXiv 2021. Available online: https://osf.io/preprints/socarxiv/m95df/ (accessed on 13 September 2021).

51. Johnson, D.P.; Ravi, N.; Braneon, C.V. Spatiotemporal Associations Between Social Vulnerability, Environmental Measurements, and COVID-19 in the Conterminous United States. GeoHealth 2021, 5, e2021GH000423. [CrossRef] 
52. USDA Rural-Urban Continuum Codes-Ag Data Commons. Available online: https://data.nal.usda.gov/dataset/rural-urbancontinuum-codes (accessed on 17 July 2021).

53. USCB American Community Survey (ACS). Available online: https://www.census.gov/programs-surveys/acs (accessed on 17 July 2021).

54. Cunningham, G.B.; Wigfall, L.T. Race, explicit racial attitudes, implicit racial attitudes, and COVID-19 cases and deaths: An analysis of counties in the United States. PLoS ONE 2020, 15, e0242044. [CrossRef] [PubMed]

55. Wheeler, S.M.; Bryant, A.S.J.O.; Clinics, G. Racial and ethnic disparities in health and health care. medRxiv 2017, 44, 1-11. [CrossRef]

56. CDC People at Increased Risk and Other People Who Need to Take Extra Precautions. Available online: https:/ / www.cdc.gov/ coronavirus/2019-ncov/need-extra-precautions/index.html (accessed on 15 July 2021).

57. Brandt, K.; Goel, V.; Keeler, C.; Bell, G.J.; Aiello, A.E.; Corbie-Smith, G.; Wilson, E.; Fleischauer, A.; Emch, M.; Boyce, R.M. SARS-CoV-2 testing in North Carolina: Racial, ethnic, and geographic disparities. Health Place 2021, 69, 102576. [CrossRef] [PubMed]

58. Oates, G.R.; Juarez, L.D.; Horswell, R.; Chu, S.; Miele, L.; Fouad, M.N.; Curry, W.A.; Fort, D.; Hillegass, W.B.; Danos, D.M. The Association Between Neighborhood Social Vulnerability and COVID-19 Testing, Positivity, and Incidence in Alabama and Louisiana. J. Community Health 2021, 7, 1-9.

59. Seto, E.; Min, E.; Ingram, C.; Cummings, B.; Farquhar, S.A. Community-Level Factors Associated with COVID-19 Cases and Testing Equity in King County, Washington. Int. J. Environ. Res. Public Health 2020, 17, 9516. [CrossRef] [PubMed]

60. Kamel Boulos, M.N.; Geraghty, E.M. Geographical tracking and mapping of coronavirus disease COVID-19/severe acute respiratory syndrome coronavirus 2 (SARS-CoV-2) epidemic and associated events around the world: How 21st century GIS technologies are supporting the global fight against outbreaks and epidemics. Int. J. Health Geogr. 2020, 19, 8.

61. CDC CDC/ATSDR Social Vulnerability Index. Available online: https://www.atsdr.cdc.gov/placeandhealth/svi/index.html (accessed on 15 July 2021).

62. Karaye, I.M.; Horney, J.A. The Impact of Social Vulnerability on COVID-19 in the U.S.: An Analysis of Spatially Varying Relationships. Am. J. Prev. Med. 2020, 59, 317-325. [CrossRef]

63. Neelon, B.; Mutiso, F.; Mueller, N.T.; Pearce, J.L.; Benjamin-Neelon, S.E.J.P. Spatial and temporal trends in social vulnerability and COVID-19 incidence and death rates in the United States. PLoS ONE 2021, 16, e0248702. [CrossRef] 